\title{
Lenguaje y silencio como materiales de la memoria colectiva y el olvido social
}

\section{Silence and language like materials of social oblivion and colective memory}

Jorge Mendoza García

Universidad Pedagógica Nacional

\section{Resumen}

En el presente artículo se hacen varias cosas: i) se argumenta la perspectiva de la memoria colectiva y el lenguaje como uno de sus principales materiales; ii) se plantea la visión del olvido social y del silencio como uno de sus principales materiales; iii) en el caso de la relación memoria-olvido, se da cuenta de su importancia en la configuración del presente en términos de recordar y olvidar; iv) se recurre a materiales de autores de otras disciplinas, dada la discusión que ahí se ha sostenido, así como en la literatura; a pesar de implementar una visión transdisciplinar, se privilegia la visión psicosocial, esto es, la memoria colectiva y el olvido social como procesos que se van construyendo en las relaciones sociales. Dos puntos anversos de una versión de la sociedad en torno al pasado que reivindica; v) al final, se argumenta la relevancia de la memoria en una sociedad y los riesgos de la instalación del olvido como fórmula de legitimación de un grupo en el poder.

Palabras clave: memoria colectiva, olvido social, lenguaje, silencio, sociedad.

\begin{abstract}
In this paper several things are done, i) it is argued the perspective of collective memory and language like one of it's main materials; ii) it is argued the view of social oblivion and silence like one of it's main materials; iii) in the affair of memory-oblivion relation is realized its importance in the configuration of the present in terms of remembering and forgetting; iv) materials of other disciplines are used because of the discussion that has been held. Literature are used too. Spite of transdisciplinary approach is given, the psycosocial perspective is privileged; this is collective memory and social oblivion like processes with which social relationships are constructed and that are two obverse points of one version of society based on the past that it claims; v) at the end it is argued the relevance of memory in society and the risks of oblivion establishment's like legitimacy formula of a power group.

Keywords: collective memory, social oblivion, language, silence, society.

Nota del autor

Jorge Mendoza García, Licenciatura en Psicología Educativa, Universidad Pedagógica Nacional (UPN).

La correspondencia en relación con este artículo debe dirigirse a Jorge Mendoza García, Licenciatura en Psicología Educativa, UPN, carretera al Ajusco, número 24, Delegación Tlalpan, colonia Héroes de Padierna, C. P. 14200, Ciudad de México, D. F., México.

Dirección electrónica: jorgeuk@unam.mx
\end{abstract}


La memoria colectiva da cuenta de los procesos sociales en que los grupos y las colectividades recuerdan. Uno de los materiales con que se va construyendo este tipo de memoria es el lenguaje, pues con él se contienen y comunican los eventos significativos de la vida en grupo, lo cual se efectúa mediante discursos abiertos, públicos y mediante prácticas sociales, actos de reiteración, como el rito. Ese es un punto sobre el pasado significativo de una sociedad. En el otro extremo se encuentra el olvido social, que da cuenta de las formas en que el poder intenta imponer el olvido de ciertas cosas, la forma privilegiada en que esto ocurre es el silencio, es decir, al omitir, prohibir y guardar secretos, se va configurando un cierto olvido en las sociedades. Ahí donde hay poder, donde hay instituciones, por ejemplo, Estado, Iglesia y Ejército, habrá la intención de legitimar una postura en detrimento de otras, en cuanto a lo que debe reconocerse y significarse del pasado; qué versiones se instituyen y qué versiones se omiten.

Esa es la relación memoria colectiva-olvido social, que delinea lo que en el presente se recuerda o se relega. Esa es la discusión del presente artículo, las formas en que la memoria colectiva se va construyendo y las maneras en que se trata de imponer el olvido social. Se discuten el lenguaje, en el primer caso, y el silencio en el segundo. La versión de la memoria aquí suscrita se planteó a inicios del siglo $\mathrm{XX}$, pero después fue relegada en la psicología y en la psicología social. La versión de olvido social que aquí se presenta está desarrollándose actualmente en términos conceptuales (Vázquez, 2001; Mendoza-García, 2015), de ahí que, en consecuencia, este trabajo recurra a autores de distintas aproximaciones en ciencias sociales, como historiadores, antropólogos, sociólogos y literatos, por ser éstos ámbitos donde se ha estado discutiendo este tipo de aproximación. Recupera, asimismo, a esos autores primigenios y privilegia la visión psicosocial de la memoria y el olvido, en el entendido, de percibir a éstos como procesos sociales de reconstrucción o anulación de un pasado significativo para un grupo o colectividad; algo que se va configurando en las relaciones sociales.

La intención de este trabajo es reformular una perspectiva sobre la relación memoria colectivaolvido social, en términos de sus implicaciones para una sociedad, las inconveniencias de apostarle al olvido, y la importancia de recordar lo significativo de una sociedad, como podría ocurrir con la sociedad mexicana.

\section{EI trazo de la memoria colectiva}

La visión de la memoria que insiste en considerarla menos una facultad individual $y$ más un proceso de edificación cultural se expuso a principios del siglo $\mathrm{XX}$, y lo hicieron al menos cuatro autores: Charles Blondel (1928/1966), Lev Vygotsky (1930/1979), Frederic Bartlett (1932/1994) y Maurice Halbwachs (1925/1960). Este último desarrolló la idea y el concepto de memoria colectiva (1925/1950a), el cual aquí se suscribe. Los otros tres autores, en sintonía 
con el concepto de Halbwachs, hablaron, respectivamente, de memoria significativa, memoria mediada semióticamente y memoria de grupo. Los inicios del siglo XX dieron cuenta de estos argumentos y propuestas, no obstante, en las décadas siguientes se les mantuvo algo relegados en el campo de la psicología y en las ciencias sociales.

La memoria es colectiva, por los marcos en que se contiene, como el espacio, el tiempo y el lenguaje; por puntos de apoyo como la afectividad, la música, la familia y la religión, sobre la base de los cuales se construye, porque son eso, marcos, en los que se contienen, en los que cobran sentido los acontecimientos dignos de mantenerse para después comunicarse. Los marcos sociales posibilitan estabilidad, son puntos fijos, coordenadas que permiten contener, por ello, el contenido puede modificarse, pero los marcos, fijos como son, se mantienen: es lo fijo donde se apoya lo que se mueve (Fernández-Christlieb, 1994). Halbwachs (1950a) sabía de ello y por eso tituló el primero de sus libros sobre el tema como Marcos sociales de la memoria; en su trabajo póstumo dedicó varios capítulos a hablar del tiempo, el espacio y el lenguaje, por ser elementos que posibilitan la memoria. Los marcos son sociales y simbólicos, son significativos en tanto se convienen colectivamente y se estipulan para las colectividades: una fecha y un lugar resultan de interés para la gente, en la medida que les dicen algo, los interpelan, les comunican algo significativo, de lo contrario serían fechas y lugares distantes, sin interés, ajenos e incomunicables.

Sobrelos espacios, PabloFernándezChristlieb (1994) señala que los lugares posibilitan la memoria colectiva, y en la cotidianeidad se van configurando: banquetas, esquinas, parques, calles, casas derrumbadas, plazas, zócalos, ruinas y otros sitios que contienen la memoria. Lo cual sucede así, toda vez que el espacio es un conjunto de dimensiones que adquiere significado, porque ahí se vivencian sucesos, y lo que produce en su interior son experiencias significativas. De esta manera, el espacio es menos natural y adquiere una sólida base social. Puede aseverarse que al espacio como territorio y orientación le corresponde una expresión simbólica, donde entra en juego el lenguaje y las relaciones que en él se establecen, por eso los grupos sienten suyos ciertos emplazamientos, porque los habitan y usan: los significan. Por consiguiente, se habla de entorno significativo cuando los eventos cobran importancia en tanto que nos impactan, afectan, nos resultan cercanos o, como dijera Halbwachs (1950b/2004, p. 132): "cuando un grupo se inserta en una parte del espacio, la transforma a su imagen, pero al mismo tiempo se pliega y se adapta a las cosas materiales que se le resisten. El grupo se encierra dentro del marco que ha construido".

Otro tanto así ocurre con el tiempo: puede hablarse de "ritmo común" y de un tiempo compartido; el tiempo no es ni demasiado lento ni demasiado rápido: son los pensamientos 
y las prácticas que lo habitan las encargadas de presentarlo apresurado o lento, según los requerimientos de la vida social. Dentro del tiempo social de un grupo el significado se reconstruye y encuentra su apoyo, en la medida que nos lo representamos como un medio continuo que no ha cambiado y ha permanecido como antes, de suerte que podemos encontrar el ayer en el hoy. Como ocurre con el espacio sucede otro tanto con el tiempo que se traduce empíricamente en fechas, y éstas representan eventos significativos para su posterior conmemoración. A su manera, lo señaló José Saramago (1991, p. 188): “el tiempo no es una cuerda que se pueda medir nudo a nudo, el tiempo es una superficie oblicua y ondulante que sólo la memoria es capaz de hacer que se mueva y aproxime". Ciertamente, la temporalidad, en este caso, no es lineal, no es cronológica, no es aquello que marcan los relojes para indicar el momento de abordar los aviones o los trenes; es otro que se contiene a la par del anterior, en la realidad social: es un tiempo sentido y significado, que vale la pena conmemorar. De tal suerte, puede hablarse de la existencia de tantos tiempos como grupos los signifiquen $\mathrm{y}$, en consecuencia, ocurre que el tiempo en cierto grupo es el que debe de ser de acuerdo con sus necesidades y tradiciones. Por eso, señalaba Halbwachs (1950b/2004), el tiempo es real, más en la medida que tiene un contenido, $u$ ofrece materia de acontecimientos al pensamiento del grupo. Este mismo razonamiento llevó a Gastón
Bachelard (1932/2002, p. 36) a argumentar que "el tiempo no es nada si en él no ocurre nada"; la materia con que se nutre son los acontecimientos significativos vividos y comunicados por un grupo que pueden expresarse en sucesos como los aniversarios, las gestas de independencia, las inauguraciones de establecimientos, los santorales de los barrios, las tragedias sentidas o el inicio de una revuelta. En tal caso, existen múltiples conmemoraciones que, para un grupo o sociedad, adquieren sentido y alrededor de las cuales se unifica.

En ese sentido, puede aseverarse que la memoria es condición del grupo. La memoria colectiva es el grupo visto desde adentro, presenta al grupo una imagen de sí mismo que acontece en el tiempo; se trata de su propio pasado, de manera que el grupo se reconozca en esa imagen. Luego, entonces, la memoria es una especie de mecanismo cultural que permite fortalecer el sentido de pertenencia a una comunidad. Para mantenerse ha de tener prácticas de memoria, conmemoraciones, y tendrá que narrarse, es decir, comunicarse, hablarse. Esto es, para comunicar lo que se recuerda, hay que echar mano del lenguaje. Un antiguo psicólogo social, George Hebert Mead (1934/1972), señaló que el lenguaje posibilita la aparición de la conciencia, pensar el sí mismo, esto es, que la persona sea un objeto para sí, una persona social, que interiorice a la sociedad: las personas, con conciencia, lo son sólo en referencia a una sociedad, toda vez que interiorizan papeles, roles, formando 
así conciencia y, de esa forma, las personas al relacionarse entre sí, interactuando, van haciendo sociedad. La memoria colectiva se configura en esa sociedad.

En esa traza de pensamiento, puede hablarse de memoria colectiva cuando se trae al presente un suceso, acontecimiento o experiencia a partir de la mirada del grupo; la memoria colectiva es entendida como un proceso social de reconstrucción de un pasado significativo para un grupo, colectividad o sociedad (FernándezChristlieb, 1994); en tal sentido, el pasado debe ser encontrado en el mundo presente, como bien lo señala Isabel Piper (2005, p. 11): la memoria es "una construcción colectiva, un proceso de interpretación de los acontecimientos que fueron o que pudieron haber sido, distanciándonos de aquellas perspectivas que la entienden como un receptáculo en el cual se almacenan los acontecimientos del pasado". Y como ya se insinuó, en esta perspectiva juega un papel medular el lenguaje.

\section{El material de la memoria colectiva: el lenguaje}

El lenguaje es social o no es lenguaje. Es un sistema de signos que permite ir designando el mundo según la sociedad vaya conviniendo y designando la realidad. El signo, como tal, tiene tres referencias: i) es signo hacia algún pensamiento que lo interpreta; ii) es signo para algún objeto; y iii) signo en algún sentido, en tanto que nos conecta con ese objeto (Peirce, 1868/1987). Es algo que representa otra cosa para quien interpreta en ciertas circunstancias. El lenguaje es un sistema que implica ir poniendo señales sobre las cosas del mundo, como justamente lo ha sugerido George Eliot, quien en 1856 escribió en su diario las ansias que tenía de saber los nombres de tantas cosas que lo rodeaban: "el deseo es parte de la tendencia que ahora crece en mí de escapar de toda vaguedad e imprecisión hacia la luz diurna de las ideas claras y vividas. El mero hecho de nombrar un objeto tiende a dar carácter definido a nuestra concepción de él” (citado en Humphrey, 1992, p. 37). Así lo entienden, por ejemplo, los poetas, artífices del lenguaje-realidad: "lo que el poema dice es lo que no existe sino al decirlo, pero una vez dicho es tan real y vital como, digamos, el mundo físico" (Strasslust, citado en Tenorio, 2004, p. 50) en sus distintas expresiones. La poesía es, en todo caso, un lenguaje que nombra el conocimiento antes de serlo y lo va haciendo. La poesía es un tipo de lenguaje que delinea la realidad social.

Ahora bien, aunque el lenguaje que usamos en la cotidianidad no totaliza la realidad simbólica y colectiva, sí constituye el pensamiento colectivo, es decir, la interpretación, definición, opinión, concepción, que la colectividad tiene de sí misma. En esa tesis, conciencia y lenguaje son una misma entidad (colectividad considerada como unidad), porque el lenguaje al desplegarse constituye a la conciencia, y la colectividad puede, por medio del lenguaje, acordar y decidir conjuntamente respecto a su identidad, situación, organización, pasado 
y futuro (Fernández-Christlieb, 1994). Si el lenguaje puede designar la realidad, el pasado, el futuro y la organización social, igualmente puede nombrar las cosas y las ideas. Lo había sugerido John Locke al hablar de sinécdoque, al decir que hay una relación entre cosa, idea y palabra (Sebeok, 1994); y quien lo describe de una manera más clara es un psicólogo colectivo, Charles Blondel (1928/1966, p. 104), pues aduce que en el inicio estuvo la palabra: "primero viene la palabra, luego la idea, después, por fin, algunas veces, la cosa. Ésta no sería para nosotros lo que es, sin la idea que tenemos de ella, ni la idea sin la palabra". La palabra como una especie de recipiente cultural, pues el lenguaje es "el espacio social de las ideas", es una "cosa social", es un asunto de la colectividad (Blondel, 1928/1966, cursivas en el original). La palabra, en todo caso, es el territorio común compartido por el hablante y su interlocutor.

Cierto, porque las personas en sociedad se ven inmersas en una realidad social que está dotada menos de objetos físicos y más de significados, que son los relevantes para la vida social, para el andar de todos los días. Tales significados se van haciendo más o menos con lenguaje, con palabras, que atraviesan a las personas y forman una especie de medioambiente. Quizá por eso es que Heráclito solía sugerir que no se le escuchara a él, sino a la palabra (citado en Cassirer, 1944/1992, p. 170), la realidad se encarnaba en las palabras que usaba, palabras que, además de definir, permiten emitir juicios que son compartidos, lo cual ocurre de esa forma dado que su contenido está configurado socialmente.

Ahora bien, se habla, se enuncia y conversa en ciertas circunstancias-elegidas las más de las veces-, así como la manera de expresarse, es decir, en cierto contexto y situación, lo que en parte permite la comprensión. De ahí que Ludwig Wittgenstein (1953, p. 39) señale que el significado de las palabras se encuentra en el lugar que ocupa en los juegos del lenguaje, y el significado no se deriva de las propias palabras o lo representado por los objetos. Las palabras y discursos aluden menos a la representación de cosas o del mundo que a construir y coordinar las distintas acciones sociales en las que nos encontramos sumergidos: "las palabras en sí mismas son algo vacío, sólo adquieren sentido en la medida que las empleamos al relacionarnos" (Vázquez, 2001, p. 90). No puede ser de otra forma, dado que el sentido de lo dicho entre las personas está investido por el contexto donde se dice, en la práctica discursiva: el sentido de una palabra no está en la palabra misma, en ella no se encuentra, tampoco lo está en quien habla o escucha, se crea más bien en la interacción.

De una forma más puntual, Mijail Bajtín (1979) aseveraba que las palabras cobran significado sólo cuando dos o más voces se encuentran en contacto, es decir, cuando la voz de un oyente responde a la de un hablante: cuando el oyente percibe y entiende el significado del discurso, al mismo tiempo se prepara para emitir una respuesta; puede estar de acuerdo o en desacuerdo con lo dicho, lo asienta, lo 
replica, se prepara para su ejecución. El oyente adopta esa actitud de respuesta a lo largo de todo el proceso de escucha, lo cual se muestra claramente en las conversaciones cotidianas, en esa relación de clara delineación social del lenguaje. La palabra es un acto bilateral, pues "se determina en la misma medida por aquel a quien pertenece y por aquel a quien está destinada. En cuanto palabra, aparece precisamente como producto de las interrelaciones del hablante $y$ el oyente" (Voloshinov, 1929, p. 121, cursivas en el original). Siendo esas interrelaciones modos distribuidos, convenidos y pactados. Cuando se habla, se acuerda, no se decreta ni se imponen los sentidos de las palabras, pues se va negociando el significado de las palabras y de los enunciados que se usan, así, "nuestra misma forma de utilizar el lenguaje para hablar del mundo se basa en la negociación" (Eco, 1998, p. 258), lo cual realizamos cada vez que hablamos. Y solemos hablar mucho.

Invariablemente y de manera cotidiana nos estamos dirigiendo a otras personas, en consecuencia, la interacción discursiva es la "realidad principal del lenguaje" (Voloshinov, 1929, p. 132). Tal interacción se manifiesta por doquier, pudiendo no sólo delinear la manera de proceder de un grupo sino su propia formación, y las agrupaciones aplican sus formas lingüísticas a sus integrantes. En ese sentido, hay comunidades de hablantes que tienen maneras de referirse a las cosas y al mundo, formas discursivas de grupos sociales, por ejemplo, los religiosos, los académicos, los estudiantes, los médicos, los abogados, los marginales, tienen ellos sus maneras de expresión propias, pero inevitablemente enmarcadas en una cultura que las alimenta, pues de lo contrario sería imposible el diálogo entre los integrantes de grupos disímiles en una sociedad. Los enunciados y acciones que llevamos a cabo se encuentran en escenarios socioculturales y están atravesados por instrumentos mediadores de los que la sociedad nos provee y no pocas veces nos impone. Tales mediadores culturales nos ayudan a hacer inteligible, cercano y familiar el mundo, las cosas por ello adquieren sentido. La vida por esos instrumentos obtiene significados.

Vygotsky dirá que cuando aprende a coordinar lingüísticamente sus acciones con las acciones de aquellos que lo rodean "el niño comienza a percibir el mundo no sólo a través de sus ojos, sino también a través de su lenguaje" (1930/1979, p. 59). Razón por la cual se puede asegurar que "imaginar un lenguaje significa imaginar una forma de vida" (Wittgenstein, 1953, p. 31). La vida constituye una realidad, al menos una realidad social, quizá esa sea la razón del porqué en diversas ciencias sociales se han intensificado los estudios sobre el lenguaje, porque, siguiendo a Wittgenstein, puede aseverarse que "el lenguaje es el límite del mundo y del conocimiento" (FernándezChristlieb, 2000, p. 154).

En ese sentido, resulta relevante lo que señala el escritor Mario Vargas Llosa: que en buena medida mediante el lenguaje delineamos y significamos la realidad, porque los conceptos 
e ideas mediante los cuales nos acercamos a ella no existen independientes de las palabras con las cuales la reconocemos; más aún: "hablar bien, disponer de un habla rica y diversa, encontrar la expresión adecuada para cada idea o emoción que se quiere comunicar, significa estar mejor preparado para pensar, enseñar, aprender, dialogar, y, también, para fantasear, soñar, sentir y emocionarse" (2002, p. 436). En efecto, este señalamiento vale para una gran cantidad de situaciones, procesos y sensaciones: los afectos, las ensoñaciones, la creatividad, el recuerdo y su memoria, el pensamiento. Hay que recordar que Agrippa, el mago, expresaba que "la función de las palabras y del discurso es la de enunciar los sentimientos del espíritu, y sacar del corazón los secretos de los pensamientos, y desplegar la voluntad de quien habla", además, "la escritura es la última expresión del espíritu, el número de la palabra y la voz, la colección, el estado, el fin, el tenor y una reiteración que crea hábito que no es completo por la voz solamente" (citado en Cohen, 2003, p. 125).

La escritura, hay que señalarlo, es un discurso plasmado en forma de texto, por eso es que Valentin Voloshinov (1929, p. 132, cursivas en el original) afirmaba: "un libro, es decir, una actuación discursiva impresa, es también un elemento de la comunicación discursiva". Al respecto, habrá que considerar lo siguiente: los libros albergan la cultura de una sociedad, un libro es mucho más que una estructura verbal, es también el diálogo que entabla con su lector, una "entonación que impone a su voz y las cambiantes y durables imágenes que dejan en su memoria"; es un diálogo infinito: la literatura no es agotable, es comunicación, es una relación, un "eje de innumerables relaciones" (Chartier, 2005, p. 238), también es inscripción de un pasado significativo, lo cual se denomina memoria.

Ahora bien, cabe aclarar que puede ocurrir que las circunstancias materiales en que dialogamos sean idénticas en distintos momentos, lo cual importa poco, en tanto que la manera de entender, y lo que es objeto de nuestra atención, así como la manera en que reunimos sucesos dispersos en el tiempo y en el espacio, y les atribuimos un significado, "dependen en gran medida de nuestro uso del lenguaje" (Shotter, 1993, p. 12), del momento discursivo: el efecto de nuestras palabras obedece al momento de la corriente conversacional en que se sitúan, en el marco de ciertas prácticas discursivas en que nos encontramos. Asimismo, la forma de hablar y la utilización y discriminación de ciertas palabras, de ciertos discursos en detrimento de otros, es posible en un marco, en una cultura que nos antecede y nos dota de significados para ser usados en ciertas situaciones y no en otras, que las propias palabras y la forma de hablar ayudan a edificar. De tal suerte, por ejemplo, "recurrimos a la demostración argumental y justificativa utilizando recursos retóricos que permiten conferir verosimilitud a nuestras declaraciones e invitan a que sean aceptadas" (Vázquez, 2001, pp. 92-93). Las prácticas discursivas que en todo momento realizamos le 
dan sentido al mundo, a las cosas que nos rodean; posibilitan las comunicaciones y relaciones que establecemos con los demás; permiten el entendimiento y la comprensión; nos permiten movernos con seguridad en nuestro entorno, y le otorgan claridad a lo sucedido en ese momento (Gergen \& Gergen, 2011; Íñiguez, Martínez, \& Flores, 2011).

Aludiendo de alguna forma a lo hasta aquí presentado, no sin cierta crítica, Pablo Fernández Christlieb (2007, p. 149) señaló: "a partir del lenguaje como único posible conocimiento de la realidad y como única realidad que puede ser conocida, la psicología social encontró un objeto sumamente apropiado que estudiar, toda vez que el conocimiento, el pensamiento, la conciencia, se puede decir que están hechos, auténticamente, de lenguaje". Teorías como la de las representaciones sociales, el socioconstruccionismo, la retórica-responsiva y la psicología discursiva, ponen en el centro y como realidad al lenguaje, las conversaciones, los discursos, las narraciones. Ello, en parte, por el énfasis que en el lenguaje comenzó a ponerse hace unos 50 años en algunas ciencias sociales (Van Dijk, 2015).

Desde esta perspectiva, se asevera que distintas prácticas discursivas se ejercen no sólo sobre la delineación del tiempo actual, es decir, del presente, sino también sobre acontecimientos y momentos que en otro tiempo sucedieron, o bien, para con el pasado: permite otorgarle sentido al pretérito, encontrarle un sitio en la actualidad. Y a esto se le denomina memoria colectiva. El lenguaje también posibilita el recuerdo social (Mendoza-García, 2015).

La memoria es lingüística, verbal, afirmará Vygotsky: "una palabra nos hace pensar en su significado, igual que un objeto cualquiera puede recordarnos otro" (1934/1995, p. 199), por eso también se concibe la memoria como conducta de relato, se puede afirmar que hablar es recordar, pues la memoria se encuentra mediada por los signos. La cultura, el lenguaje, como "eslabón mediador", condición para la conformación de la mente humana, de la memoria (Iliénkov, 1984, p. 27). No podía ser de otra forma, toda vez que no hay memoria por fuera del lenguaje, o al menos se ve de alguna manera imposibilitada, pues su reconstrucción se dificulta. La memoria se abre paso a través de la verbalización, como uno de sus fuertes caminos; no obstante que las formas de hacer memoria colectiva excedan la palabra misma, aunque haya una memoria imborrable e incluso innombrable y se manifieste de distintas formas, "se la llama y se la modela desde el lenguaje" (Calveiro, 2001, pp. 18-19).

En tanto que las palabras son sociales, constituyen la forma más directa de comunicar significados, cosas como las imágenes para ser comunicadas tienen que "ser expresadas a través de palabras" (Bartlett, 1932/1994, p. 295). Es la misma reflexión que manifiesta Paul Ricoeur (1999, p. 27) y por ello habla de memoria declarativa, puesto que ésta alude siempre a algo, declara: "decir que nos acordamos de algo, es declarar que hemos visto, escuchado, sabido 
o aprehendido algo, y esta memoria declarativa se expresa en el lenguaje de todos, insertándose, al mismo tiempo, en la memoria colectiva".

Continuando con la argumentación, el lenguaje permite albergar los recuerdos, ampliar la memoria misma. Un conjunto de experiencias, se sedimentan y objetivan a través del lenguaje, incorporadas a un conjunto de tradiciones, de ahí que se asevere que la memoria se encuentra inextricablemente unida al lenguaje, por ejemplo, al discurso que usa el grupo al cual se pertenece, a través de sus marcos sociales o esquemas. Bartlett (1932/1994, p. 373) dirá que se puede acceder al "esquema de grupo", que conforma sus recuerdos, a través del lenguaje común del grupo, al cual tienen acceso sus integrantes, esto se debe a que "las convenciones verbales constituyen el marco más elemental y estable de la memoria colectiva" (Halbwachs, 1925/1960, p. 111), es el sitio donde se contienen y delimitan. Por eso, ahí se pueden localizar los recuerdos, por ejemplo, en las fechas y en los lugares, y se mantienen de manera más duradera mediante el lenguaje, cuando se comunican, cuando se narran. Las convenciones lingüísticas, las relaciones y las palabras que la sociedad nos presenta tienen un poder evocador y proporcionan el sentido de lo evocado: la memoria en buena medida depende de la palabra, y en tanto que la palabra sólo es posible en el marco de una sociedad, cuando las personas se alejan de las relaciones donde forjaron sus experiencias, se complica recordar (Halbwachs, 1925/1960, p. 87). Al alejarse del grupo o de la colectividad, las personas se alejan del lenguaje que posibilita narrar lo acontecido tiempo atrás.

Esta estrecha relación de lenguaje con memoria, Vygotsky (1930/1979) la denominó memoria verbal, es esa memoria mediada por signos, estos signos son estables, sólidos, permiten que en ellos se depositen los eventos más tardes convertidos en recuerdos, pues el lenguaje representa uno de los elementos conservadores más firmes en ciertas culturas: "sin este conservatismo no llegaría a cumplir su misión principal, la comunicación"; dado que estos símbolos y formas lingüísticas "deben poseer cierta estabilidad y persistencia para resistir la influencia disolvente y destructora del tiempo" (Cassirer, 1944/1992, p. 330). La memoria colectiva es un acto del presente.

Jorge Semprún (1995, p. 24), alumno de Halbwachs y sobreviviente de un campo de exterminio nazi, da cuenta de cómo el lenguaje mantiene la memoria: para él, como otros que vivieron en campos de exterminio, dos palabras, krematorium y ausmachen, los remitirían a la cruda realidad de los campos. Exiliado en un país con lengua distinta (de España se vio obligado a emigrar a Francia), dice sobre su lengua materna y los recuerdos, al compararlos con las canciones infantiles para recordarlos, que le era necesario repetir, aun en voz baja, cosas en español para poder recordarlas: desde números de calles, fechas de citas o de cumpleaños: "tenía que repetírmelas en español para grabármelas en la memoria" (Semprún, 2001, p. 120). Se pone 
de manifiesto que es por medio del lenguaje que "las memorias individuales se superponen con la memoria colectiva" (Ricoeur, 1999, p. 27). La memoria es conducta de relato. Y la denominada memoria personal es un punto de vista dentro del grupo.

La memoria tiene uno de sus fuertes materiales en el lenguaje, en el intercambio, en las palabras. Y cuando éstas se van, cuando se desvanecen, cuando se les quema, por ejemplo, en los escritos, el olvido tiende a asomarse.

\section{El trazo del olvido social}

Si la memoria colectiva se edifica sobre la base de la expresión pública y del lenguaje, el olvido social lo hace sobre la base del secreto y el silencio. El secreto es aquí suscrito como aquello que deviene incomunicable $\mathrm{y}$, por ende, permanece en el ámbito de lo privado, en tanto el silencio es aquello a lo que se le imposibilita su expresión en el espacio abierto por razones de imposición, aquello que no se desea o quiere que se exprese. En buena medida, el presente de las sociedades se finca sobre la tensión memoria-olvido. La tesis desarrollada aquí indica que entre menos versiones e interpretaciones sobre el pasado se manifiesten, ese pasado se va achicando, silenciando, y así se va configurando el olvido social. En esa lógica, las versiones alternativas y múltiples sobre el pasado se mantienen en secreto, una de las pocas posibilidades que tienen para subsistir y al paso del tiempo poder irrumpir. Este tipo de olvido se presenta lo mismo en la academia que en la religión o en las naciones, ahí donde hay instituciones se pone de manifiesto. Para dar cuenta de este presupuesto, se va delineando una argumentación que da cuenta de actores, sucesos y narraciones omitidas o silenciadas en distintos momentos y lugares.

Proponer el mantenimiento de la memoria implica minimizar el olvido; y a la inversa: la dominación del olvido conlleva necesariamente empequeñecer el recuerdo. En términos sociales, grupales y de poder, puede hablarse de una pugna entre olvidar y recordar. Como categorías, tanto memoria como olvido pertenecen al ámbito de las ciencias sociales, se han ido tematizando desde la historia, la sociología, la antropología y la psicología social. En todos los casos, la relación memoria-olvido da cuenta de la manera como se edifica la sociedad en términos de su pasado y de su presente.

Desde la perspectiva aquí suscrita, el olvido social es entendido como esa imposibilidad de comunicación sobre lo que en el pasado ha ocurrido o en el presente se va forjando, y cuya incomunicación se dispone desde posiciones de privilegio, como las de poder. En tal sentido, el devenir del olvido se encuentra ligado al silencio, a aquello que se ha querido, intentado y en algunos casos logrado acallar. Se pueden referir casos como los de las mujeres, los marginales, los leprosos, los pensamientos opositores y, bien podrían incluirse, personajes que incomodan en distintos periodos de la historia ortodoxa. 


\section{Lo comunicable e incomunicable: público y privado}

Al menos desde los griegos, allá por el siglo V. a. C., el espacio se estableció como público en oposición a privado. Tiempo de largo aliento si se considera que aún a inicios del siglo XXI dicha separación contiene una cierta dureza, vigencia, que el pensamiento social sigue inscribiendo ciertas actividades consideradas "públicas" en ese sitio y las consideradas "privadas" en el suyo. La palabra, en Grecia, nació pública, enunció lo que hay que conocer, saber, no esconder, sino manifestar, comunicar, intercambiar. Es por medio de la comunicación que una comunidad acuerda qué va a regir como realidad para sus participantes; se intercambian significados sobre la realidad. Es lo comunicable. Dicho intercambio difícilmente se presenta en una esfera estrecha, en un espacio privado, pues en este sitio no se intercambia, más bien se guarda con celo lo que se sabe.

Lo privado es esa zona en donde la gente se repliega, se retira, donde ya no es necesario portar la indumentaria, las formas, los comportamientos, los discursos requeridos en el espacio público. Es el sitio familiar, doméstico, zona en que está aquello que queremos sólo para nosotros y que contiene los asuntos concernientes al sí mismo, de lo que no se quiere hablar ni divulgar porque no pertenece al sitio abierto y, por tanto, se protege: “el poder privado ha de resistir hacia fuera, los asaltos del poder público" dijo Geroge Duby (1985, p. 13). De alguna manera, lo privado es eso opuesto a lo público, es eso que se escolta o esconde, aquello que se intenta alejar de la mirada o el interés de los demás.

Con base en esta idea, la palabra, al menos desde los griegos, ha estado del lado masculino, como lo fue el espacio público (Reyes, 1942/1997). En esta lógica, el silencio y el espacio privado fueron impuestos a la mujer. Al paso de los siglos, las formas no sufrirán grandes cambios, no es fortuito que quien se ha dedicado al estudio de las mujeres señale: "a las mujeres se les ve menos en el espacio público, el único que durante mucho tiempo mereció interés y relato" (Perrot, 2006, p. 18). De hecho, el siglo XIX no fue muy distinto, pues es "en este siglo que se afirma la primacía de la palabra masculina, la predicación femenina se lleva a cabo mediante la retórica del cuerpo, la elevación de la mirada y el fervor del gesto" (Corbin, 1987, p. 425), manifestaba en lo semiprivado. Esa privacidad de la vida cotidiana, en especial sus secretos, sexualidad, cuerpo, higiene, se mantiene algo lejos de los confesionarios, pero su desciframiento continúa, y lo hace vía la contabilidad, la contabilización de la existencia: horas, días, alrededor de las prácticas que pueden ser vistas como pecaminosas. Y si hay libros de cuentas en la casa, por qué no llevar la contabilidad de la vida. Es así que surge el diario íntimo, una forma del secreto, de eso que no puede ni debe comunicarse a los demás. Lo incomunicable, que incluso al final de la vida se destruye, por considerarlo poco trascendental (Perrot, 2006). 
La vida privada no puede sino ser entendida en el sentido estricto de la vida secreta (Vincent, 1987), lo que puede ser nodal en el régimen de lo privado sería el secreto. La palabra "secreto" aparece hacia el siglo XV, proveniente del latín secretus, del verbo secerno que significa "separar", "poner aparte". El secreto es un saber o conocimiento que se oculta con respecto a otro conocimiento. Se conforma de tres elementos: i) el saber, ii) el disimulo de este saber, y iii) la relación con el otro que proviene de este disimulo. Por eso, secreto también refiere a retención de una información. Se imposibilita que se diga más allá de donde se debe.

Tres cosas al respecto: i) hay un secreto por disimulo, por guardar ciertas cosas que corresponderían al campo de lo íntimo, que nada tienen que ver con el interés público. Ese secreto no atenta contra lo comunicable en el espacio abierto, pues no es de interés común lo resguardado, como los dolores nocturnos o las ensoñaciones; es voluntario de algún modo. Ese tipo de secreto, o el orden de este secreto, no atenta contra la vida social, porque no se impone ni esconde algo de interés para la vida pública de una sociedad. ii) Un secreto que se violenta es, especialmente puesto en práctica por las formas duras de pensamiento: los pensamientos cerrados, fanáticos, totalitarios, son ilustrativos sobre el desplazamiento de lo público a lo privado mediados por el secreto. En los totalitarismos, de cualquier signo, derecha o izquierda por caso, la separación entre lo público y privado tiende a desparecer, no hay secreto de correspondencia, se dan investigaciones policiales a cualquier hora del día y de la noche, incluso en el marco familiar, entre otras cosas (Vincent, 1987).

Una buena aproximación a la caracterización de vida privada en sociedades totalitarias consistiría en afirmar que la privacía no existe, pero eso omite la astucia de las personas para mantener en lo privado múltiples cosas que después se expresarán en el espacio abierto, cuestión de esperar algún tiempo y ciertas condiciones sociopolíticas. Lo cierto es que las sociedades totalitarias obligan a la secrecía, a que esta esfera sea más amplia de lo que puede expresarse en la vida pública: el totalitarismo genera más secretos de los que acosa. iii) Hay otro tipo de secreto, que se ejerce en dos ámbitos. Primero, el que llevan a cabo los grupos de poder, al tratar de esconder cosas o información de interés común, que compete a la colectividad o sociedad. Y segundo, el tipo de secreto que generan las prohibiciones, las censuras, las imposiciones. Estos dos últimos secretos provienen desde el poder, como política ejercida, por ejemplo, desde el Estado (Darnton, 2014, p. 235). Estos tipos de secretos sí atentan contra la comunicación y lo públicoaquí se retoman-, son esos que encubren sucesos, periodos, situaciones, acontecimientos, esconden deliberadamente, con fines de ejercicio de poder, de legitimar lo ilegítimo.

Una manera funesta del secreto es la prohibición, iniciada con los griegos hacia el 403 a. C., con la prohibición de recordar las desgracias, los males ajenos y del pasado 
(Loraux, 2008, p. 15); son tiempos en que lo político es indisoluble de lo religioso, siendo ese terreno donde se impone no recordar, después será el de escribir ciertos relatos, como en algunos grupos religiosos ocurrirá siglos más adelante. La forma más cruenta es aquella que desde el poder oculta con fines de control y dominación, los ejemplos más firmes se encuentran en la esfera política, toda vez que "el secreto puede ocultar aquello que no se cuenta porque desataría reacciones contrarias, quizás por su ilicitud" (Grijelmo, 2012, p. 20). En otros ámbitos de la vida social también ha estado presente, como en el caso de la academia, donde un conocimiento disciplinar se esconde y no aparece en los manuales, como sucedió con la perspectiva de la psicología de los pueblos de Wilhelm Wundt durante décadas, o en la ciencia, cuando se omiten ciertos conocimientos y se "redescubren" décadas o siglos después, tal y como ocurrió con el hallazgo del oxígeno, que se mantuvo en el "oscurantismo" durante un siglo (Sacks, 1996, p. 3). Lo mismo, cuando desde ciertas posiciones se ordena el disimulo: Pitágoras prescribía a sus novicios un silencio de varios años, para que aprendieran a guardar los secretos de la asociación, imponiendo así una disciplina y una pureza de la vida. Quien pasara esta prueba, conseguir estar años sin hablar al respecto, estaba preparado para otras tentativas.

El silencio lleva invariablemente al secreto, ha dicho Georg Simmel (1908/1986). El secreto, en este caso, es una ocultación deliberada, una forma de silencio. Una manera sólida y violenta que opera en diferentes sociedades en distintos tiempos es la censura: una supervisión del comportamiento público (Gómez de Silva, 1985); el censor evalúa y juzga lo que es pertinente expresarse en el espacio abierto, sea comportamiento, manifestación, palabra, signo o escritura. La censura va ligada a la prohibición y, por supuesto, al poder, elemento éste constitutivo de la imposición en los pensamientos totalitarios y autoritarios. El ojo avizor se impone sobre lo que en el espacio abierto se enuncia, razón por la cual hay que replegarse al espacio privado, donde ya no se comunica y así se imposibilita ensanchar la esfera de la comunicación: se prohíbe la enunciación franca, se afinca el silencio.

Se escuchan y registran conversaciones o se prohíbe la impresión o circulación de textos. Se ha censurado históricamente; textos griegos $\mathrm{y}$ chinos, antes de nuestra era, fueron eliminados. De varios de ellos sólo se tienen noticias por citas que otros autores realizaron sobre dichos escritos. Protágoras, el acuñador de la frase "el hombre es la medida de todas las cosas", el retórico mayor, escribió catorce libros, todos ellos fueron prohibidos y luego destruidos. En la China antigua, de igual manera, cuando una nueva dinastía llegaba al poder, se prohibían los escritos anteriores, muchos de ellos terminaron en la hoguera, otros más, decomisados. La Edad Media fue especialmente cruel con los textos previos a su tiempo, los que no encajaban con el pensamiento dominante de entonces, el pensamiento de la Iglesia Católica fue crucial 
a este respecto, los textos griegos se quemaron $\mathrm{u}$ ocultaron. Lo escrito ha sido visto como peligroso, de ahí que se haya intentado en distintos momentos su regulación. Cuando ello no es posible prohibiciones y hogueras son fórmulas a las que se recurre.

A inicios de 1500, se instituyó la figura del "censor": un letrado fiel y de supuesta buena conciencia que se encargaba de prohibir obras llamadas apócrifas, supersticiosas, condenadas, así como las consideradas vanas e inútiles (Infelise, 1999). Para 1559, el tribunal del Santo Oficio publicó el primer Índice de libros prohibidos que aplicaba para toda la cristiandad (Manguel, 1996). Pocas voces se levantaron contra la reprimenda. Desde Inglaterra, país que tenía animadversiones con Roma, se escucharon algunas gargantas, como la del poeta John Milton, quien salió en defensa de la obra: "matar un buen libro es casi lo mismo que matar a un hombre. Y en cierto sentido es aún peor, porque quien mata a un hombre, mata a una criatura dotada de razón, hecha a imagen de Dios, pero quien destruye un buen libro mata a la propia razón" (citado en Infelise, 1999, p. 73). Milton, por lo demás, había visitado a Galileo en su prisión de Italia en 1638.

En 1660, Carlos II de Inglaterra decretó que se debía instruir en las ideas del cristianismo a los indígenas, sirvientes, esclavos de las colonias británicas. Quienes poseían esclavos se escandalizaron, no concebían que sus cautivos accedieran a la lectura, con temor creían que accederían a ideas revolucionarias. Asumían que si los esclavos podían leer la biblia, leerían textos abolicionistas o que podían encontrar fundamentos a favor de su libertad. La resistencia al decreto de Carlos II fue tan fuerte que tiempo después en algunas colonias estadounidenses, como en Carolina del Sur, se promulgaban leyes que explícitamente prohibían enseñar a leer a los negros, fueran éstos libres o esclavos (Manguel, 1996). En consecuencia, los esclavos debieron inventar estrategias para no ser sorprendidos en el aprendizaje de la lectura.

Casos los hay y muchos: censura y poder, prohibición e incomunicación. Esa idea del poder, del pensamiento autoritario, totalitarista, bien puede sintetizarse en lo que en la segunda mitad del siglo XX el militar golpista argentino, Jorge Rafael Videla, en su momento manifestó: "un terrorista no es sólo el portador de una bomba o una pistola, sino también el que difunde ideas contrarias a la civilización cristiana occidental" (citado en Manguel, 1996, p. 298). Eso explica por qué John M. Coetzee (1996), escritor sudafricano que sabe de censuras en un país gobernado por un pensamiento tiránico, afirmó que silencio y censura van juntos, en el acto de silenciar y censurar se despliega toda una pasión por parte de quien la ejerce.

\section{El material del olvido social: el silencio}

Es pertinente una aclaración: aquí no se tematizan ni asumen los distintos silencios que pueden manifestarse en la vida social, por ejemplo, el recurso para enfrentar una situación incómoda; el que se presenta ante 
el asombro; para marcar posiciones de espera ante una situación ambigua; como reserva; como refugio para no externar una respuesta negativa o convencional; una manera de establecer distancia; como abandono espiritual; como exilio del habla; como respeto, secreto profesional o confesional. El silencio que aquí se aborda es otro, y vale aclararlo: el silencio no es sólo una cierta modalidad de lo que denominamos sonido es, en buena medida, una cierta modalidad del significado; el silencio, como el lenguaje, posee propiedades del signo (Castilla del Pino, 1992). En efecto, el silencio no tiene significado unívoco, pues los usos culturales de la palabra, de las situaciones, dotan de significado al silencio, y éste se encuentra "cargado de intenciones cuando la palabra esperada permanece muda" (Le Breton, 1997, p. 56). El silencio está sujeto a factores sociales, culturales, históricos y políticos.

Al entender el sentido del silencio como relacional (así ocurre con el lenguaje), el silencio que en este trabajo se aborda es aquel que cuyo fin deliberado es ocultar algo, y en su versión más extrema, lo hace desde ciertas posiciones privilegiadas, como la del poder (Coetzee, 1996). Es decir, existen instituciones o pensamientos totalitarios $\mathrm{y} / \mathrm{o}$ excluyentes que practican el silencio con el fin de ocultar cosas, objetos, información que a la sociedad le competen, sacándolos del espacio público. Este silencio se presenta como gravamen, es ese silencio impuesto por la violencia que pone en suspenso los significados, y es tendiente a romper el vínculo social (Le Breton, 1997). Con la violencia política y social viene la imposición del silencio, de la incomunicabilidad. Con certeza, el peso de la palabra o del silencio se encuentra en función de las circunstancias en que se manifiestan (Jaworski, 1993).

Simmel dijo que "la forma más grosera y más radical del secreto es aquella en que el secreto no se refiere a una actividad concreta del hombre, sino al hombre entero" (1908/1986, p. 412), lo cual sucede cuando se esconde lo que debe estar en el espacio común, público, aquello igual o similar que ocultar la historia o memoria de la mitad de la humanidad. Por ejemplo, las mujeres han sido relegadas al silencio, a la sombra de lo doméstico, donde no ha interesado que se les narre, han sido testigos de menor valor en contraste con el sitio público donde se deslizan las "grandes hazañas", los "grandes hombres" (Perrot, 1999). Así inicia su libro Mi historia de las mujeres Michelle Perrot (2006, p. 13): "hoy en día se presenta como obvia: una historia 'sin las mujeres' parece imposible. Sin embargo, no siempre existió. Al menos en el sentido colectivo del término [...] esta historia es relativamente reciente" y comienza su paso "del silencio a la palabra".

Al respecto puede aseverarse que en el silencio las mujeres van acompañadas de otros grupos, pues "dicho silencio envuelve el continente perdido de las vidas engullidas por el olvido en que la masa de la humanidad queda abolida, pero cae con más peso sobre ellas" (Perrot, 2006, p. 18). En efecto, en la omisión 
han estado otros grupos, sectores que resultan incómodos para las visiones dominantes, en cierto sentido podrían ser parte de esta estrategia de omisión las brujas (Cohen, 2003), los negros (Memel-Fote, 1999), los esclavos (Saco, 1974), las minorías en distintos tiempos (Nirenberg, 1996). El silencio sobre estos sectores ha sido lapidario en diferentes momentos. Y cuando han sido enunciados, lo han sido con la perspectiva del poder; se narran desde una mirada ajena, en ocasiones inculpadora (Ginzburg, 1989; Cohen, 2003). Esa descripción y representación es posible en la medida que el dominio del silencio y la palabra ha sido y es una característica de la autoridad institucional (Le Breton, 1997), desde ahí se les traza.

Se ha hecho siglos atrás, se sigue haciendo en el presente; al tiempo que se les caricaturiza, se les silencia.

El poder tiene recursos y mecanismos que posibilitan reducir al silencio a aquellos actores para quienes lo ha dispuesto así, por ejemplo a la oposición o a sus críticos. El estatus no puede ponerse en tela de juicio, hay que excluir a quien se lo proponga, pues el silencio es esencialmente ausencia (Grijelmo, 2012); como en la ausencia de respuesta, silencio y ausencia son sinónimos en este caso, y la ausencia es conducente de la omisión: no se enuncia algo para que no se comunique o no se comprenda, sino para que se oscurezca, para que no suceda, que es lo que conduce al olvido.

Todo silencio, en medio de una institución, implica una organización de la palabra $y$, por tanto, un manejo del silencio: "cualquier autoridad moral o institucional es dueña de la palabra y del silencio, y se arroga la posibilidad de entablar conversaciones" (Le Breton, 1997, p. 58), de narrar lo que a sus intereses conviene y de ocultar lo que considera atenta contra esos intereses. En ese sentido, lo comunicable se vuelve incomunicable; lo común personal; lo público privado; lo que antes se manifestaba de manera abierta termina por mantenerse en lo íntimo. Comunicaciones que no deben más estar en el escenario público, ni en las conversaciones en las calles ni en las primeras planas de los periódicos. De ahí que se entienda, a la perfección, porque se esgrime que de alguna manera y en ciertas condiciones el escrito intente oponerse al secreto (Simmel, 1908/1986), a lo privado, dado que se pone en el escenario público $\mathrm{y}$, en múltiples casos, lo escrito es lo antagónico a lo que el poder desea que se exprese. El poder le apuesta al olvido, $\mathrm{y}$ quienes escriben le apuestan a que se forje memoria, pues mientras la escritura mantiene memoria, el silencio erige olvido.

La historia del olvido se encuentra ligada al silencio, a aquellos o aquello que se ha querido sosegar. Quizá por eso el escritor argentino Juan Gelman (2001) ha declarado que escribe, porque escribiendo intenta acabar con el silencio que navega sobre la amnesia. En este proceso, la reflexión es lacónica: lo que no se habla no existe, o cuando menos no cobra significado alguno. Siguiendo a Wittgenstein (2012, pp. 74-75), si "los límites del lenguaje significan 
los límites de mi mundo", entonces, en la realidad no cabe aquello de lo que no se habla: "lo que no se cuenta no existe. Lo que nunca ha sido el objeto de un relato, de una historia, no existe. Los tiranos lo saben muy bien y por eso borran los rastros de aquellos a quienes intentan reducir a la nada" (Perrot, 1999, p. 61). Distintos actores han sido borrados, por acción del silencio, en los relatos de la remembranza. Aquel suceso, periodo, sector, grupo, persona que no se nombra, del que se calla, al que no se le incluye en el discurso y la conversación, se le ha olvidado.

Al hacer memoria, al reconstruir el pasado, se le endosan continuidades a lo que ha sido significativo en los grupos y en la sociedad. Mediante memoria se ligan pasado, presente y futuro, y simultáneamente se edifican nuevos significados, de esta forma resulta comprensible y familiar lo que tiempo atrás sucedió. Cuando el silencio, tendiente al olvido, hace acto de presencia sobre el pasado, éste se vuelve incomprensible y ajeno. A eso se le denomina discontinuidad; ahí donde falta la memoria, la discontinuidad se presenta y genera olvido. Y es a lo que hoy se le denomina novedad: ese no saber de dónde provienen las cosas; ese rubricar los acontecimientos, personajes o pensamientos como algo que surgen en el momento y en el presente, y desconocer su largo viaje desde tiempos atrás. Lo que ahí se atraviesa es el silencio, lo no dicho, lo no comunicado, ya sea por una cuestión de tabú, como lo anuncia Marc Ferro (2002, p. 9): aquello ante lo cual se hace silencio, sea por temor, por pudor o por prohibición, que remite a lo que no está autorizado decir, o a la censura que alude a la vigilancia y lo proscrito, la supresión se impone ante el lenguaje.

Silencio y secreto son formas constitutivas de la vida social, el poder los usa para su beneficio y regocijo: "el poder, al impedir que la palabra circule, enturbia las relaciones y provoca la sospecha general, pues es difícil en muchas ocasiones arriesgarse a plantear sin ambages una objeción ante quienes tienen una posición personal que desconocemos" (Le Breton, 1997, p. 66).

Cabría, al momento de hurgar estos procederes, explorar las formas de ir rompiendo ese silencio y cómo la palabra se posiciona en el espacio público. Privado y público son dos esferas que constituyen una sola realidad. Por eso lo relacionado con el secreto tiene que ver con lo público, porque de esa esfera se saca lo que se quiere esconder, lo que se ha censurado. En consecuencia, puede argumentarse que la censura es un fenómeno perteneciente, relacionado con la vida pública (Coetzee, 1996), debido a que se quiere mantener en el ámbito de lo privado, de lo oculto, ciertas versiones de la realidad pública. Mantener en privado, en silencio o en secreto variadas versiones sobre la realidad, implica necesariamente encoger la realidad misma, achicarla, porque se va empobreciendo, y eso ocurre con las narraciones sobre el pasado. Personajes, grupos, sectores, minorías, mujeres, masacres, atrocidades, torturas, juicios, quemas, ahí se encuentran, y poco o nada de ello se 
narra: la memoria así se va plegando, el olvido va carcomiendo a las sociedades. De múltiples interpretaciones y significaciones dables a la vida social, se reducen a unas cuantas, las autorizadas, las impuestas, las estatuidas.

Se sacan de la vida pública, de la locución abierta, expresiones sobre situaciones antes compartidas. Se les mantiene en secreto o se les obliga a sellarse en la secretud. Se les arrincona en el campo privado, en lo incomunicable. Ese es el paso de lo público a lo privado, de lo comunicable a lo incomunicable. En la esfera de lo incomunicable se quedan eventos, tiempos, que a la sociedad competen, pues se edifican muros de silencio a su alrededor: de ello no se pronuncia palabra alguna cual si no hubieran existido. Así se va manufacturando el olvido, al menos esa es su intención.

\section{La sociedad: entre recordar y olvidar}

El siglo XX fue de especial salvajismo y crueldad, ejecutados en nombre de la humanidad, del bien común, del progreso, de la nación, del Estado, y en contra de las amenazas: los horrores han sido una experiencia central en este siglo, y eso duele, cala y hondo, se siente profundamente, razón por la cual se apuesta a que la memoria no permita que tales tragedias sean olvidadas. Diversos sectores de la sociedad en distintos sitios (piénsese en Europa del Este después del derrumbe del bloque socialista, en el Cono Sur luego de la caída de los regímenes militares, o en el México posterior a la salida del Partido Revolucionario Institucional del poder) han demandado se arroje luz y palabras sobre los excesos del poder que llevaron a la vivencia de múltiples tragedias, para que no se olvide, para que se recuerde. No sólo para evitar repetirlas sino porque moralmente debe aprenderse de ellas. Lo más grave que le puede suceder a una sociedad, a decir de Jacques Le Goff (1990), es que caiga en la desmemoria, lo peor es el olvido, señala y advierte la importancia de evitar que a los olvidos de los verdugos no les siga el olvido de las víctimas. Aquí y allá, diversos grupos, como se ha visto a fines del siglo XX e inicios del XXI, no están dispuestos a ello. En este sentido, la memoria debe ser considerada no sólo como celebración, sino también como reorientación del pensamiento social, del quehacer en sociedad. Esto permitiría en el presente, más allá de la condena, evitar injusticias, no parecidas a las del pasado, pero sí sinrazones del poder tendientes a la exclusión, eliminación, al olvido de lo diferente.

En el México reciente, se ha sucedido una serie de prácticas que se creen novedosas, se asumen como surgidas en el presente. No obstante, si se hurga un poco en el pasado incómodo mexicano, se caerá en la cuenta de que dichas prácticas han estado presentes y, más bien, se les silenció, se les omitió y, en cierta medida, se les olvidó. En efecto, la práctica de la desaparición de personas operó en los años sesenta y setenta del pasado siglo XX. A cientos de opositores políticos se les desvaneció, se les 
puso en pausa y se les aniquiló físicamente. Cientos de desaparecidos, opositores políticos ellos, fueron parte de las consecuencias de enfrentar el viejo régimen. Estas desapariciones no se han esclarecido, no han sido reparadas, no se ha reconocido institucionalmente la práctica de una represión cruel contra aquellos que se enfrentaron con las armas al poder. A eso se le ha denominado guerra sucia (MendozaGarcía, 2015). Tampoco se ha reconocido que en México durante las décadas señaladas hubo grupos guerrilleros que operaron en varios estados del país. Pues bien, ante ese olvido, la puesta en pausa del reconocimiento y los relatos sobre ese periodo, lo que se manifiesta en años recientes-la desaparición-, se percibe como novedad. Reconstruir dicho periodo cruento, se vuelve necesario porque es un trozo del pasado de nuestra sociedad, y ello nos compete. Se vuelve necesario hacer un ejercicio de memoria colectiva al respecto. $Y$ en ello se han esforzado algunos grupos, en especial de familiares de desaparecidos, para armar el rompecabezas de esos momentos crueles.

En contra de la lógica olvidadiza del poder, los grupos y sociedades insisten en la permanencia de lo que experimentan, de lo que hacen, de lo que crean. Le apuestan al recuerdo. Según se mire el pasado, puede observarse que un elemento esencial de la civilización consiste en levantar monumentos para no olvidar, desde construir monumentos, como hacer nudos, son manifestaciones de los rasgos fundamentales y característicos de la humanidad (Vygotsky, 1930/1979). Las sociedades, en consecuencia, le apuestan a la memoria, y en ello trabajan. El tiempo de la sociedad se destila en el sentido en que se va reduciendo su desconocimiento acerca del mundo. Para la colectividad, el futuro se convierte en pasado cuando lo desconocido se hace conocido, cuando el sinsentido se vuelve sentido. El conocimiento de su pasado es algo importante, cardinal.

Distintos grupos enquistados en el poder, con todos los recursos que ello implica, intentan imponer el olvido. Y, como se dijo al inicio de este texto, cuando el olvido se extiende en una sociedad, la memoria se encoge, el pasado se achica. Hay menos acontecimientos que narrar y menos versiones que expresar. El olvido se impone, la memoria se construye y reconstruye. El poder hace esfuerzos por establecer qué se recuerda y qué se olvida. Los grupos y las colectividades mantienen en la memoria aquello que les resulta significativo. Son dos lógicas distintas, incluso opuestas. No es gratuito, entonces, que se esgrima que "la lucha del hombre contra el poder es la lucha de la memoria contra el olvido" (Kundera, 1978, p. 10). En distintas sociedades y momentos, se instaura el olvido como sinónimo de tragedia. De ahí que ante las críticas que se esgrimen hacia las sociedades que mucho conmemoran, la respuesta, en consecuencia, bien podría ser que el antónimo de olvido no sea la memoria sino la justicia. 


\section{Referencias}

Bachelard, G. (1932/2002). La intuición del instante. México: Fondo de Cultura Económica.

Bajtín, M. (1979). Problemas de la poética de Dostoievski. México: Fondo de Cultura Económica.

Bartlett, F. (1932/1994). Recordar. Estudio de psicología experimental y social. Madrid: Alianza.

Blondel, Ch. (1928/1966). Introducción a la psicología colectiva. Buenos Aires: Troquel.

Calveiro, P. (2001). Desapariciones. Memoria y desmemoria de los campos de concentración argentinos. México: Taurus.

Cassirer, E. (1944/1992). Antropología filosófica. Introducción a una filosofía de la cultura. Buenos Aires: Fondo de Cultura Económica.

Castilla del Pino, C. (Comps.). (1992). El silencio. Madrid: Alianza.

Chartier, R. (2005). Inscribir y borrar. Cultura escrita y literatura (siglos XI-XVIII). Buenos Aires: Katz.

Coetzee, J. (1996). Contra la censura. Ensayos sobre la pasión por silenciar. México: Debate.

Cohen, E. (2003). Con el diablo en el cuerpo. Filósofos y brujas en el Renacimiento. México: Taurus/UNAM.

Corbin, A. (1987). Entre bastidores. En P. Ariés \& G. Duby (Eds.), Historia de la vida privada 4 (pp. 391-574). Madrid: Taurus.
Darnton, R. (2014). Censores trabajando. México: Fondo de Cultura Económica.

Duby, G. (1985). Prefacio. En P. Ariés \& G. Duby (Eds.), Historia de la vida privada 1 (pp. 11-14). Madrid: Taurus.

Eco, U. (1998). A todos los efectos. En J. Carrière (Dir.), El fin de los tiempos (pp. 215272, 280-283.) Barcelona: Anagrama.

Fernández-Christlieb, P. (1994). La psicología colectiva un fin de siglo más tarde. Barcelona: Anthropos/Colegio de Michoacán.

Fernández-Christlieb, P. (2000). El territorio instantáneo de la comunidad posmoderna. En A. Lindón (Coord.), La vida cotidiana y su espacio-temporalidad (pp. 147-170). Barcelona: Anthropos/UNAM.

Fernández-Christlieb, P. (2007). Los dos lenguajes de las dos psicologías de lo social. En Z. Monroy \& P. Fernández-Christlieb (Eds.), Lenguaje, significado y psicología (pp. 147-157). México: UNAM.

Ferro, M. (2002). Los tabúes de la historia. Buenos Aires: Nueva Visión.

Gelman, J. (2001). Preludio. En P. Calveiro (Coord.), Desapariciones. Memoria y desmemoria de los campos de concentración Argentinos (pp. 9-13). México: Taurus.

Gergen, K., \& Gergen, M. (2011). Reflexiones sobre la construcción social. Madrid: Paidós.

Ginzburg, C. (1989). Historia nocturna. Barcelona: Península.

Gómez de Silva, G. (1985). Breve diccionario etimológico de la lengua española. México: 
Fondo de Cultura Económica/El Colegio de México.

Grijelmo, A. (2012). La información del silencio. Cómo se miente contando hechos verdaderos. México: Taurus.

Halbwachs, M. (1925/1960). Les cadres sociaux de la mèmoire. París: Félix Alcan.

Halbwachs, M. (1950a). La mèmoire collective. París: PUF.

Halbwachs, M. (1950b/2004). La memoria colectiva y el tiempo”. En J. Mendoza García (Coord.), El conocimiento de la memoria colectiva (pp. 103-137). México: UAT.

Humphrey, N. (1992). Una historia de la mente. Barcelona: Gedisa.

Iliénkov, E. (1984). La dialéctica de lo ideal. En Escuela de cuadros. Recuperado de http://marxismocritico.com/2014/01/22/ladialectica-de-lo-ideal-evald-ilyenkov/

Infelise, M. (1999). Libros prohibidos. Una historia de la censura. Buenos Aires: Nueva Visión.

Íñiguez, L., Martínez, A., \& Flores, G. (2011). El discurso en la psicología social: desarrollo y prospectiva. En A. Ovejero \& J. Ramos (Eds.), Psicología social crítica (pp. 98-116). Madrid: Biblioteca Nueva/UAQ/UMSNH.

Jaworski, A. (1993). The power of silence. London: Sage Publications.

Kundera, M. (1978). El libro de la risa y el olvido. Barcelona: Seix Barral.

Le Breton, D. (1997). El silencio. Aproximaciones. Madrid: Sequitur.
Le Goff, J. (1990). Prefacio. En A. Brossat (Ed.), En el Este la memoria recuperada (pp. 11-17). Valéncia: Alfons El Magnànim.

Loraux, N. (2008). La ciudad dividida. El olvido en la memoria de Atenas. Madrid: Katz.

Manguel, A. (1996). Una historia de la lectura. México: Planeta.

Mead, G. (1934/1972). Espíritu, persona y sociedad. Barcelona: Paidós.

Memel-Fotê, H. (1999). La memoria vergonzosa de la trata de negros y esclavos. En F. BarretDucrocq (Ed.), ¿Por qué recordar? (pp. 145155). Barcelona: Granica.

Mendoza-García, J. (2015). Sobre memoria colectiva. Marcos sociales, artefactos $e$ historia. México: Universidad Pedagógica Nacional.

Nirenberg, D. (1996). Comunidades de violencia. La persecución de las minorías en la Edad Media. Barcelona: Península.

Peirce, Ch. S. (1868/1987). Algunas consecuencias de las cuatro incapacidades. En Ch. Peirce (Coord.), Obra lógico semiótica (pp. 58-87). Madrid: Taurus.

Perrot, M. (1999). Las mujeres y los silencios de la historia. En F. Barret-Ducrocq (Ed.), ¿Por qué recordar? (pp. 55-61). Barcelona: Granica.

Perrot, M. (2006). Mi historia de las mujeres. Buenos Aires: Fondo de Cultura Económica. Piper, I. (2005). Introducción. ¿Olvidar o recordar? En I. Piper (Ed.), Memoria y derechos humanos: ¿prácticas de dominación 
o resistencia? (pp. 9-13). Santiago de Chile: ARCIS/CLACSO.

Reyes, A. (1942/1997). La antigua retórica. Obras completas (vol. XIII). México: Fondo de Cultura Económica.

Ricoeur, P. (1999). Definición de la memoria desde un punto de vista filosófico. En F. Barret-Ducrocq (Ed.), ¿Por qué recordar? (pp. 24-28). Barcelona: Granica.

Sacks, O. (1996). Escotoma: una historia de olvido y desprecio científico. En O. Sacks (Ed.), Historia de la ciencia y el olvido (pp. 3-21). Madrid: Siruela.

Saco, J. (1974). Historia de la esclavitud. Madrid: Jucar.

Saramago, J. (1991). El evangelio según Jesucristo. México: Alfaguara.

Sebeok, T. (1994). Signos: una introducción a la semiótica. Barcelona: Paidós.

Semprún, J. (1995). La escritura o la vida. Barcelona: Tusquets.

Semprún, J. (2001). Viviré con su nombre, morirá con el mío. Barcelona: Tusquets.

Shotter, J. (1993). Realidades conversacionales. La construcción de la vida a través del lenguaje. Buenos Aires: Amorrortu.

Simmel, G. (1908/1986). Sociología. Estudios sobre las formas de socialización, 2. Madrid: Alianza.

Tenorio, M. (2004). El urbanista. México: Fondo de Cultura Económica.

Van Dijk, T. (2015). Cincuenta años de estudios del discurso. En Discurso \& Sociedad, 9(12), 15-32.
Vargas-Llosa, M. (2002). La verdad de las mentiras. Madrid: Suma de Letras.

Vázquez, F. (2001). La memoria como acción social. Relaciones, significados e imaginario. Barcelona: Paidós.

Vincent, G. (1987). ¿Una historia del secreto? En P. Ariés \& G. Duby (Eds.), Historia de la vida privada 5 (pp. 135-353). Madrid: Taurus.

Voloshinov, V. (1929a/1992). El marxismo y la filosofía del lenguaje. Madrid: Alianza.

Vygotsky, L. (1930/1979). El desarrollo de los procesos psicológicos superiores. México: Grijalbo.

Vygotsky, L. (1934/1995). Pensamiento y lenguaje. Barcelona: Paidós.

Wittgenstein, L. (1953). Investigaciones filosóficas. Barcelona: UNAM/Crítica.

Wittgenstein, L. (2012). Tractatus logicophilosophicus. Madrid: Alianza.

Recibido el 13 de agosto de 2015

Revisado el 25 de octubre de 2015

Aceptado el 13 de diciembre de 2015 